\title{
Psychological Effects on Victims of the Johor Flood 2006/2007
}

\author{
R. Nasir ${ }^{1}$, A. Z. Zainah ${ }^{1} \&$ R. Khairudin ${ }^{1}$ \\ ${ }^{1}$ School of Psychology and Human Development, Faculty of Social Sciences and Humanities, Universiti \\ Kebangsaan Malaysia, Bangi, Malaysia \\ Correspondence: R. Khairudin, School of Psychology and Human Development, Faculty of Social Sciences and \\ Humanities, Universiti Kebangsaan Malaysia, 43600 UKM Bangi, Selangor, Malaysia. Tel: 60-3-8921-5286. \\ E-mail: rozainee@ukm.my
}

Received: February 13, 2012

Accepted: March 29, 2012 Published: July 1, 2012

doi:10.5539/ass.v8n8p126

URL: http://dx.doi.org/10.5539/ass.v8n8p126

\begin{abstract}
Flood is one of the many types of natural disaster that affects human lives. Often the focus of such disaster has been on physical losses. Nevertheless, psychological effects of natural disaster have become equal importance that needed much attention. The objective of the current study is to explore psychological effects in terms of cognition, feeling or emotion and behavior. The study adopted an exploratory qualitative approach. A total of five respondents were interviewed using face-to-face technique. Results showed that victims suffered cognitive, emotional and behavioral shortfalls such as fear, anxiety, hopelessness, helplessness and depression. Emotional issues were the most apparent dimension among the three psychological dimensions under study. The implication of this study suggests strong social support from people who are well equipped with knowledge and skills in the management of stress, anxiety and other psychological problems.
\end{abstract}

Keywords: natural disaster, flood, psychological impact, cognition, emotion, behavior

\section{Introduction}

Natural disasters such as earthquakes, tsunami, and flood are some of the contributing factors to high level of stress and other psychological problems in individuals. Natural disasters threaten lives thus causing a lot of fear. Physical effects such as loss and destruction of properties and life are among the many consequences of natural disasters. These impacts may last for a short or long term. Victims are often struggling hard to accept and cope with these negative effects. Consequently, many organizations such as World Health Organization (WHO) are very concerned about the health of victims of natural disasters.

During the past several years much interest among scientists have been in the relationship between natural disaster and mental and physical health. Many researches have shown that there was a relationship between psychological problems and the disaster among different groups of people who were directly involved with the disaster such as the victims as well as those involved in rescuing them (Norris, et.al 2005; Stevens \& Stone, 2005; Pynoos et. al, 1987). Disasters can also have substantial and long terms effects on the psychological and physical health of survivors (Hull et. al, 2002; Morgan et. al, 2003; Galea et. al, 2005). There were evidences to show that apart from the direct trauma effects of hurt and pain, victims also experienced physical problems. Fear, anxiety, sensitivity and anger are some of the common reactions of the victims (National Center for Children Exposed to Violence [NCCEV] 2001). However, the effects on the victims differ from individual to individual based on age, gender, and where they live. In terms of gender, according to Davidson $(2001,2004)$ women were two times (10-14\% PTSD) more likely to develop PTSD than men (5-6\% PTSD). In the areas where natural disaster such as flood is a common phenomenon, the people who live in this location would be more prepared for the disaster both psychologically and physically. Thus their reactions would be less significant after the occurrence of the disaster. However, for those people who live in areas where floods are rare, the effects might be significant to them. The impacts may be greater for victims who are children, adolescence, adults and elderly who are already experiencing psychological problems such as depression, anxiety and other psychological problems. Studies also indicated that the impairments can be endured for years (Warchal \& Graham, 2011). As such the psychological 
problems need to be addressed in order to prevent victims having more problems which could last for the rest of their lives that may even lead to feelings of committing suicide.

A majority of people who survive a disaster recover with few or no lasting effects on their psychological health. However there is always a portion who experience long-term distress (Wahlstrom et al., 2008). A few researchers had indicated that the immediate and the short term effects of natural disaster is the rise in physical and mental problems. The long term effect is physical in nature even though the mental problem had reduced. The physical and mental problems endured by the victims are very serious. A study by Tapsell (2001) on hidden impact of 1998 Easter Flood in UK found that effects on psychological health includes stress, anxiety, fainting, panic attacks, depression, lethargy and agoraphobia worsened. Maslow's hierarchy of needs theory is very appropriate in explaining the loss of properties and homes among the victims. Their priorities are usually the fulfilment of physiological and safety needs. Before all the basic needs are fulfilled, the other needs such as the psychological needs are not important. Psychological needs will only be felt when they have met the physical needs such as food and shelter.

Some disaster victims experience Post Traumatic Stress Disorder (PTSD) such as depression and anxieties. Other problems experienced by them are sadness, helplessness and hopelessness. According to Norris (2005) the effects of natural disaster are depression, anxieties, unspecific distress, cognitive distortion, panic and various health problems. It is not easy to give a general picture of the psychological effects of natural disaster specifically that of the Johor flood without having done a comprehensive study on its effects on those living in the affected areas. This is due to different perceptions of flood. Besides, individuals also differ in terms of their life histories, social and economic status and their skills in managing problems and life responsibilities. All those factors have important roles in determining the level of resilience and strength when they encounter life problems which include natural disaster.

Flood could increase the level of stress and anxiety among victims and their stress and anxiety will increase as the weather changes. The change of weather is an indicator that there will be another disaster which could expose them to more flood. Thus due to the failure and the inability to control the situation and their vulnerability to threat, the victims would show symptoms of depression, sadness, hopelessness, feeling of being overwhelmed in emotions due to lack of emotional and physical strength to cope with the situation. Very often victims find it very difficult to focus their attention on any specific thing, to complete any task and faced with the demand to be strong and independent. Also, they would develop anxieties and uncertainties as to whether their lives would ever be the same again.

Specifically, this research aimed to explore the thinking, emotion and behavior of victims of the Johor flood. The information gathered from this research is very useful in the understanding of the psychological effects of flood on the victims.

\section{Method}

This is an exploratory study using qualitative approach. This research was conducted in Kampung Tembiuh of Kota Tinggi, Johor. Data for this small research was obtained through face to face interview and observation. The main objective of this research was to find out the emotions, perceptions, thoughts and opinions of the respondents about their experiences. Secondly, the researchers hoped to find out the effects of the victims' experiences with flood on their thinking (attitude and perception), behavior and feelings. Face to face interview technique is the best technique to use in order to explore the three aspects. Through the interviews researchers could gather information on the respondents' thoughts, emotions and behavior which one could not get by merely using paper/ questionnaires and pencil technique.

Five respondents were interviewed who were all victims of the Johor flood. They were women whose ages ranged from 65 to 81 years old who lived in the housing area around Kampung Tembiuh. During the interview session the victims were asked to share their experiences during the flood and recall everything that they had gone through and they had seen happening to them and around them.

The respondents were chosen using convenient sampling method whereby those people who were willing to talk to the researchers and share their feelings and their thinking were taken to participate in this research. During the interview sessions the respondents were also observed in terms of their non-verbal behaviors by the researcher as well as the co-researchers. 
Table 1. Respondents demographic information

\begin{tabular}{cccccc}
\hline Respondent & Age & Marital Status & Living relative & Income & $\begin{array}{c}\text { Received aid from } \\
\text { relatives }\end{array}$ \\
\hline 1 & 66 & Married & Yes & SWD & Once in a while \\
2 & 73 & Widowed & Yes & SWD & Once in a while \\
3 & 75 & Single & No & SWD & No \\
4 & 77 & Widowed & No & SWD & No \\
5 & 81 & Widowed & No & SWD & No \\
\hline
\end{tabular}

$\mathrm{SWD}=$ Social Welfare Department

Table 1 shows that the oldest respondent was 81 years of age, followed by 77 years old, 75 years old, 73 years old and the youngest was 66 years old. Three of the respondents were widowed, one had never been married and the last one was still married and lived with her husband. All subjects received financial support from the Social Welfare Department (SWD) under the Ministry of Women, Family and Community Development. The subject who was still married earned extra income by peeling onions which paid her RM10.00 per large sack. All respondents could be categorized as being below the poverty line. Two of the respondents still had living relatives and they are still in contact with their relatives once in a while. The rest of the respondents did not have any living relatives.

\section{Results and Discussion}

The results showed some themes related to cognitive functioning or thinking, various behavior and emotions felt by the respondents. There was a change of cognitions experienced by the respondents. For example one respondent asked, "Why me?", "Why must it happen to me?": questions that were related to personal values and feeling of vulnerability.

According to Root (1992), trauma could change victims' perception towards reality because they would look at themselves, others and the event which caused trauma in a very different perspective. Root believed that trauma is related to the stress that causes a lot of difficulties and its effect will never disappear unless all the causes of stress disappear.

Table 2. Cognition, emotion and behavior of respondents

\begin{tabular}{lcl}
\hline Cognition & Feeling/emotion & Behavior \\
\hline Is it going to flood again? & Fear, anxious & $\begin{array}{l}\text { Always on the alert } \\
\text { Always look at the river } \\
\text { Always look for sounds } \\
\text { of rain and thunder }\end{array}$ \\
& & Collect all belongings \\
If it happen where do I go? & Scared, anxious & Gather all belongings \\
No place for shelter & Sad & Could not sleep; Cry \\
Everything is gone & Sad & Cry \\
I am going to die!! & Hopelessness; depress & Cry \\
There is nothing that I can & Helplessness; depress & \\
do! & Helpless; sad & No action \\
It is fated & Sad; regret & Smile; cry \\
Life was better before & Sad ; Happy & Smile; cry \\
Reminiscence & Hopelessness; helplessness; & Cry \\
Why must it happen to me? & Depress &
\end{tabular}

Results of this study are shown in Table 2 which shows the cognition (thinking), emotions and behavior of the five victims in this research during the interview sessions. All of them showed similar trend of thinking, emotions and behavior. 
Trauma will have a long lasting effect on a person and can affect the basic principles of the person on others as well as the environment which is around them. There is a direct link between the emotions and cognitions. Among the emotional effects that are experienced by the victims were anxieties, sadness, helplessness, depression, and post traumatic stress disorder.

One of the obvious emotions seen among the respondents was the worry of possible recurrence of flood. According to Green et al. (1983) this is "an anxiety over threats from flood". This was reflected by the words that were uttered by one of the five respondents as follows:

"In terms of my feelings, it did affect me..... until now whenever it rains, I get worried and panicked. Will there be flood gain?"

In terms of the mental health status of the victim, emotional reaction towards stress is very significant in contributing towards anxiety and sleep disturbance. For example, among children emotional reaction to stress usually is seen in the form of sleep disturbance, (such as change of sleep pattern), tension, restlessness, anxiety and trembling (Mahadir Ahmad, et al. 2004).

Spielberger and Diaz-Guerrero (1976) differentiated between fear and anxiety, whereby fear is a form of emotion which is caused by a real event whose threat is real and very obvious. However, anxiety is a result of a complex psychological process, or emotional response (behavior) towards something that had not happen. Basically the process of anxiety includes those stressful feeling, restlessness and fear.

According to Sigmund Freud (1924), anxiety is a very unpleasant emotion, is seen experienced by individuals with anxiety neurosis, haunted by fear or expectation of something which is fearful and this can be considered as restlessness. Symptoms of psychological anxieties include, heart palpitations, muscle tension, shivering, breathlessness or difficulties in breathing, sweating, nauseating and giddiness. Anxiety differs from other unfavorable feelings such as anger or depression.

Sadness was seen common among the victims in this study. Loss of objects and properties belonging to them such as pictures and portraits which had sentimental values and are symbolic to them and which are irreplaceable became the cause of their sadness. This was seen as follows:

"To our family, flood was very terrible, we lost old and valuable things which belong to our family. Those things are not replaceable. It's very sad..."

Flood not only cause loss of properties and belongings but also loss of life. The death of loved ones will have a very significant effect on the victims especially if it involved people who are very close to them. After the death of someone close, the most important response that is often shown by a person is that of sadness and a feeling of loss for a period of a few months to a year. A normal period of mourning is six months before a person can function normally. Some people shows chronic sadness which is called Complicated Grief or CG that is the inability to accept death or the loss of someone close or a beloved person.

CG is not listed as mental disorder in DSM-IV (Diagnostic Statistical Manual of Mental Disorders), but it is associated with a serious mental and physical disorder. Among the symptoms of CG are extreme thoughts of the dead person, difficulties in accepting death, lack of trust of others, feeling regret, difficulties in leading a normal life, emotional 'numbness', emptiness and hopelessness. All those symptoms will be experienced by the person for about six months and because of that the person finds it difficult to get back to a normal life (Prigerson et al., 1995).

The inability to effectively control sadness will lead to depression, that is extreme sadness, melancholia and hopelessness which can disrupt the social functions and daily activities of the person. A depressed person will always feel sad and lack motivation to do anything. Symptoms of depression are lack of energy, feeling tired, sad, angry, lazy, negative attitude and lack of focus and not cheerful. Depression can also be considered as a feeling/emotion, syndrome or clinically sick (Dacey \& Kenny, 1997). Among the long term symptoms of depression are head ache, gastric/stomach problem and chronic pain, always feeling anxious, feeling empty, hopelessness and helplessness. During a more serious stage of depression, the individual will always be thinking of death and thinking having no more reason to live. Social psychological factors such as natural disaster causing trauma is one of the main factors that can lead to depression and affect the person's thought, feeling and behavior which could in turn cause a lot of disruption to the person's daily life. If depression is not managed effectively, it can further affect a person psychologically, for example the person may experience low self-esteem and there is also the risk of committing suicide.

Depression is referred to several conditions whereby the depressed will be melancholy, hopelessness, lack of motivation and extremely sad. Those feeling will be accompanied by sweating, difficulties in breathing and slow heart rate. Lwinsohn, et al. (1978) came up with a few common depression syndromes such as dysphoria 
(uncomfortable not cheerful), inactive, difficulties in interacting with others, feeling guilty, stressed and other physical problems such as lack of appetite and head ache.

A depressed person normally is faced with problems such as sleep difficulties, lack of energy, lethargic, laziness, with no specific reasons. An empirical study about depression (Psyzcynski et al., 1999) showed that depressed persons are different from those who are not in terms of their cognition, social and self-motivation. Thus that depression is capable of changing and influencing a person's thought and behavior.

A depressed flood victim will experience emotional disturbance which is in the form of sadness, hopelessness and lack of interest in the world around him. According to Becker (1984) depression can happen when three things happen to an individual: loss the meaning of life, loss of self-esteem and loss of playfulness. Loss of self-esteem is very important to the internal behavior of a person, meanwhile lack of playfulness is one of the main factors that causes depression. Death of a loved one, loss of properties and belongings, loss of shelter, caused by flood will lead to all sort of stress if treatment action is not done.

Individual's reaction to flood differs from person to person. Shock, worry, refusal to belief and stress are some of the general feelings experienced by the victims of the flood in Kota Tinggi, Johor. The following is some of the things that were said:

"I did not expect that flood would happen so fast. I saw the river water rose and I did not expect it to happen so fast...I still cannot believe it...."

Other feelings felt by the respondents were hopelessness and helplessness. Helplessness usually will lead to learned helplessness (LH). Those who experience LH will normally feel that they cannot control the environment and any move to control and manage the situation will be useless. The effect will be the person will become passive when they are in an uncomfortable situation or in a destructive situation, even though in actual fact they are capable of controlling and change the situation. When the individual feel that he had no energy or capability to control the situation, he becomes sad and depressed.

During the Johor flood the victims may have experienced a feeling of helplessness because for them the disaster may be Allah's (God's) will or "Takdir", which is beyond their ability to escape, and they have no ability to manage, let alone to fight them. The perception of inability to fight and to control is referred to as LH. In their study on earthquake survivors in California, Knight and Gatz (2000) found that older individuals took fewer preparatory steps for a disaster than did the younger individuals. According to Knight and Gatz this lack of preparation might reflect a fatalistic perspective.

LH theory which had been applied to human behavior had shown that depression is the loss of mood. A depressed person will learn that whatever he does is not effective or a waste of time and energy or of no use. In everyday life, the individual will realize that it is very obvious that he is incapable of controlling his behavior.

LH is also referred to those persons who found that he has no more hope and cannot solve the problem that he is facing. In other words, he feels that regardless of what he does, no matter how hard he tries, he has no hope of controlling or managing the situation. His attempts in doing so are all useless. The flood victim may have also experienced Post-traumatic Stress Disorder (PTSD). PTSD is a severe anxiety disorder that can develop after the exposure to any event that can result in psychological trauma such as extreme fear or shock. The event can cause the threat of death to oneself or to someone else. Events which can lead to PTSD include and not limited to violence, natural disaster, human made disaster, accidents or war. Apart from leading to a long and serious effect on the individuals it can also affect the well being of their loved ones. Survivors' rates of PTSD in technological and human-made disasters range from $29 \%$ to $54 \%$ where as survivors' rates of PTSD of natural disasters are lower, between $4 \%$ and $8 \%$ (Warchal \& Graham, 2011).

PTSD is identified by symptoms whereby the victims will recall the traumatic event through flashbacks or nightmares, as well as the behavioral manifestation of avoidance, withdrawal, psychical numbness, loss of interest to play or to have fun, also an increase in other symptoms such as difficulties in getting and staying asleep and focusing, shock reaction, heart ache, anger and hyper-vigilance.

Many people who experience PTSD will recall the traumatic events in their mind during the day time as well as at night in their sleep. These symptoms are called flashbacks, which include images, smell and feelings which come about because of small things or events which remind the PTSD victims of the traumatic event. Those suffering from PTSD may not be living in reality and believe that the traumatic event which caused trauma will happen again.

Not everyone who went through trauma would experience PTSD. The symptoms associated with the trauma would normally be experienced during the first three months after trauma however if it lasts longer than one month, the 
person who experiences it may be considered as experiencing PTSD. Some victims will be cured after six months while others take longer to get over it until the trauma becomes very chronic. PTSD is less frequent and more enduring than the more commonly seen acute stress response.

In 1980, the American Psychiatric Association (APA) published Post Traumatic Stress Disorder (PTSD) in the "Diagnostic and Statistic Manual of Mental Disorder" (DSM-III) Manual, third edition. This diagnosis looks at psychiatric symptoms which are commonly experienced by individuals who are in trauma whereby PTSD indicated how dangerous bio-psychological effects on trauma victims. The formal diagnostic criteria requires that the symptoms last more than one month and can cause significant impairment in social, occupational, or other important areas of functioning (http:://en.wikipedia.org/wiki/Posttraumatic stress disorder).

Anxieties among flood victims can cause stress, fear and restlessness (Mandler \& Watson, 1966). The flood can disrupt normal life and activities and can bring about adaptive behavior and psychological disorder (Kaplan, 1983). Hence, bad experience in one's life can cause big psychological consequences and will disturb a person psychologically. Prolonged anxiety and stress can affect the present and future life of a person.

Persons who are depressed will become passive, pessimistic and lack of motivation to get involved in hobbies or other activities which can give satisfaction to them. The level of depression of those who are undergoing depression can be seen in their interpersonal relationships. There are individuals who are not happy and not satisfied when they are in the company of others and there are also others who find it difficult to relate to others. Some people who are depressed will feel guilty, useless and self-blame when they failed to fulfil their responsibilities.

Most of the flood victims felt distress because they felt that their lives had been threatened. At the same time they were worried and sad because of their loss and lack of basic needs such as food and drinks. However, past research had shown that for most victims, these psychological anxieties and symptoms such as fear, sleeplessness, helplessness and hopelessness will not be prolonged and will go away within a few days to several weeks. Some victims even feel guilty when they thought of family members who were killed and whom they failed to save. In this case they often feel angry and fearful (Ahern et al., 2005). Individuals who have a history of mental illness would have a tendency to experience more serious symptoms and mental problems.

Distress would often be experienced by children and adolescence who usually could not rely on their parents for emotional strength since their parents themselves were experiencing emotional stress. As such, the effects on the mental health of children and adolescence are being prolonged so much so that some of them show major behavioral change since many of them failed to express their feelings verbally. Hence they express their feelings in the forms of behavior such as withdrawal, refusal to communicate, inability to control feelings, inability to focus, aggression, dreams and nightmares (Durkin et al., 1993).

Despite having gone through all the hardships during the flood, most of the respondents felt that life had to go on. Generally the old victims of the Johor flood were able to get back to normal life. Phifer (1990) believed that older victims of disasters especially those ages 75 and older adapt well after disaster. This according to Phifer, is due to a higher incidents of past resolved stressful experiences and a lower incidence of current unresolved stressful experiences.

\section{Conclusion}

Results of the interview with respondents in the research area revealed that victims of the flood had gone through a bad experience which could be seen from several dimensions. In general most of the things that the victims talked about concerned the loss of properties and physical problems. However, most victims felt that emotional issues were very apparent for example fear that the flood might occur again, and physically exhausted as a result of a lot of cleaning and repairing of their houses. In terms of their reactions to flood, the victims felt that it was unbelievable, shocking, stressful, worrying while at the same time they felt that life had to go on.

In general most people become more resistant to the impact of flood. This resistance depend a lot on the individuals who experienced it which include life experiences and their perception towards all those events that took place.

This study was intended to be largely exploratory, and results cannot be generalised and representative of other studies. However, a better and more reliable picture concerning the effect of flood on its victims requires a comprehensive study which involves psychological testing on a bigger sample which represents the general population of the victims. A comprehensive research using both qualitative and quantitative methods would give a better representation and picture of the psychological effects of flood on those who went through it. Once the effects of flood had been ascertained one could have a comprehensive intervention counseling plan for the victims. 
For the counselors, a true picture of the mental and psychological state of the victims would be able to give an idea of the kind of intervention techniques or approaches to use.

What can be learned from the Johor flood is that those involved in flood should have been more prepared both physically and psychologically. They should have strong social support from people who are equipped with knowledge and skills on how to manage and prevent from stress, anxiety, PTSD and other problems relating to the effects of natural disaster.

\section{References}

Ahern, M., Kovats, R. S., Wilkinson, P., Few, R., \& Matthies, F. (2005). Global health impacts of floods: epidemiological evidence. Epidemiolic Reviews, 27, 30-46. http://dx.doi.org/10.1093/epirev/mxi004

Becker, M. H. (1984). The health belief model: a decade later. Health Education Behavior, 11, 1-47. http://dx.doi.org/10.1177/109019818401100101

Dacey, J., \& Kenny, M. (1997). Adolescent development. USA: Brown \& Benchmark Publishers.

Davidson, JRT. (2001). Recognition and treatment of posttraumatic stress disorder. JAMA, 286(5), 584-588

Davidson, JRT. (2004). Long-term treatment and prevention of posttraumatic stress disorder. Journal of Clinical Psychiatry, 65(supp 1), 44-48. http://dx.doi.org/10.1001/jama.286.5.584

Durkin, M. S., Khan, N., Davidson, L. L., Zaman, S. S., \& Stein, A. (1993). The effects of a natural disaster on child behavior. Evidence for post traumatic stress. American Journal of Public Health, 83, 1549-1553. http://dx.doi.org/10.2105/AJPH.83.11.1549

Freud, S. (1924). Criticisms of the anxiety neurosis-collected papers. London: International Psychoanalytic Press.

Galea, S., Nandi, A., \& Vlahov, D. (2005). The epidemiology of posttraumatic stress disorder after disasters. Epidemiologic Review, 27, 78-91. http://dx.doi.org/10.1093/epirev/mxi003

Green, C. H., Parker, D. J., \& Emery, P. J. (1983). The real cost of flooding to household: Intangible Cost. Geography and Planning Paper No.12. Flood Hazard Research Centre, Enfield: Middlesen Polytechnic.

Hull, A. M., Alexander, D. A., \& Klein, S. (2002). Survivors of the Piper Alpha oil platform disaster: long-term follow-up study. British Journal of Psychiatry, 181, 433-438. http://dx.doi.org/10.1192/bjp.181.5.433

Kaplan, H. B. (1983). Psychosocial Stress Trends in Theory and Research. New York: Academic Press.

Lwinsohn, P. M., Munoz, R. F., Youngren, M. A., \& Zeiss, A. M. (1978). Manual for Group Cognitive Behavior Therapy for Major Depression: Control your depression. New York: Prentice Hall.

Mahadir Ahmad, Normah Che Din, \& Fauziah Shaari. (2004). Reaksi Tekanan Terhadap Kesihatan Mental Juvana. Jurnal Sains Kesihatan Malaysia, 2(2), 53-62.

Mandler, G., \& Watson, D. (1966). Relationship between locus of control and anxiety. Journal of Personality and Social Psychology, 6,1, 91-92.

Morgan, L., Scourfield, J., \& Williams, D., et. al. (2003). The Aberfan disaster: 33 year follow-ip of survivors. British Journal of Psychiatry, 182, 532-536. http://dx.doi.org/10.1192/bjp.182.6.532

National Center for Children Exposed to Violence [NCCEV]. (2001). Latest information: Help in the aftermath of violence: Tools to deal with trauma. Retrieved from www.nccev.org/resources/press-releases/pr_9-11-01.htm

Norris, F. (2005). Range, magnitude and duration of the effects of disasters on mental health: Review Update 2005. Retrieved September 2, 2005, from http://www.redmh.org/research/general/effects.html.

Phifer, J.F. (1990). Psychological distress and somatic symptoms after disaster: Differential vulnerability among older adults. Psychology and Aging, 5, 412-420. http://dx.doi.org/10.1037/0882-7974.5.3.412

Posttraumatic Stress Disorder. Retrieved June 2010, from http://en.wikipedia.org/wiki/Posttraumatic stress disorder

Prigerson, H. G., Frank, E., Kasl, S. V., Reynolds, C. F., Anderson, B., Zubenko, G. S., ... Kupfer, D. J. (1995). Complicated grief and bereavement-related depression as distinct disorders: preliminary empirical validation in elderly bereaved spouses. American Journal of Psychiatry, 152, 22-30.

Psyzcynski, T., Greenberg, J., \& Solomon, S. (1999). A dual process model of defense against conscious and unconscious death-related thoughts: an extension of terror management theory. Psychological Review, 106, 835-845. http://dx.doi.org/10.1037/0033-295X.106.4.835 
Pynoos, R. S, Frederick, C., Nader, K., Arroyo, W., Steinberg, A., Eth, S., ... Fairbanks, L. (1987). Life threat and posttraumatic stress in school-age children. Archives of General Psychiatry, 44, 1057-1063. http://dx.doi.org/10.1001/archpsyc.1987.01800240031005

Root, M. P. (1992). Reconstructing the impact of trauma on personality. In L.S. Brown \& M.S. Ballou (Eds.), Personality and Psychotherapy: Feminist Reappraisals (pp. 229-265). New York.

Spielberger, C. D., \& Diaz-Guerrero, R. (1976). Cross-cultural anxiety. Washington, D. C: Hemisphere Publishing Corporation.

Stevens, S., \& Slone, L. (2005). The tsunami and mental health. What can we expect. A National Center for PTSD fact sheet.

Tapsell, S. (2001). The hidden impacts of flooding: experiences from two English communities. Integrated Water Resources Management (proceedings of a symposium held at Davis, California, April 2000), IAHS Publ. No. 272.

Wahlstrom, L., Michelsen, H., Schulman,A., \& Backheden,M. (2008). Different types of exposure to the 2004 Tsunami are associated with different levels of psychological distress and posttraumatic stress. Journal of Traumatic Stress, 21(5), 463-470. http://dx.doi.org/10.1002/jts.20360

Warchal, J.R., \& Graham, L.B. (2011). Promoting positive adaptation in adult survivors of natural disasters. ADULTSPAN Journal, 10(1), 34-51. http://dx.doi.org/10.1002/j.2161-0029.2011.tb00005.x

World Health Organization (WHO). (1983). Depressive disorders in different cultures: Report of the WHO collaborative study of standardized assessment of depressive disorders. Geneva. 